\title{
Dialysis: Survival and Palliation
}

\author{
Mellar P Davis ${ }^{1}$,Dennis Cotter ${ }^{2 *}$, Mae Thamer ${ }^{2}$, Nicholas Hamilton-Cotter ${ }^{2}$ \\ ${ }^{1}$ Director of Palliative Care, Geisinger Medical Center, Danville. \\ ${ }^{2}$ Medical Technology and Practice Patterns Institute, Bethesda.
}

Received: November 09, 2016; Accepted: November 11, 2016; Published: November 14, 2016

*Corresponding author: Dennis J Cotter, President,Medical Technology and Practice Patterns Institute, Inc. 5272 River Road, Suite 365 Bethesda, MD 20816, Tel: (301) 652-4005 ; Fax: (301) 652-833;E-mail:dcott@mtppi.org

\section{Introduction}

Kidney supportive care is palliative and can extend survival of patients with end-stage kidney disease. Patient-centered care adapts the treatment plan to patient goals and values, life style and community [1]. Conversations with the patients about renal replacement therapy should result in plan of care which gives priority components of medical care important to patients over components which patients feel are less important. Renal replacement therapy may or may not improve quality of life and has a variable influence on the length of life. Patients who present with and-stage renal failure have multiple symptoms which impair quality of life (fatigue, pain, sleep disorders, restless leg syndrome, weight loss, anorexia, dysgeusia and depression) which may not improve with dialysis. Some of the symptoms are shared by comorbid illnesses common in older patients with chronic renal failure such as cancer, heart failure and chronic obstructive lung disease (COPD) [2-11]. Symptoms of these comorbid illnesses will not improve with renal replacement therapy. Symptoms and poor quality of life in renal failure are underreported but prognostically important [12].

Discussions centered on initiation of dialysis should include the palliative benefits or lack of palliative benefits to dialysis and the potential to extend life and how long life might expect to live on average. Thamer and colleagues used the US Renal Data System and Claims data from the Centers for Medicare and Medicaid Services to generate a survival prediction tool for older individuals who were initiated on dialysis. A scoring system based on age, albumin, activities of daily living, comorbid illnesses (cancer, heart failure) and hospitalizations within the last year accurately predicted 3-month mortality [13]. Some of the predictors overlap with the geriatric frailty syndrome as published by Fried et. al. [14].Individuals who had a shorter survival on dialysis are older, with evidence of systemic inflammation (low albumin), had comorbid illnesses, reduced. Many were probably frail prior to dialysis which would predict reduced appetite, sarcopenia, dysgeusia, increased falls, cognitive impairment and mortality $[15,16]$. Another recent study found that a simple frailty scale and comorbidity score could be used to predict survival and better inform the shared decision-making process for patients with advanced kidney disease [17].

\section{Quantity and Quality}

The risk of mortality of end-stage renal failure and the life prolonging nature of dialysis may be the deciding factor for patients who value quantity of life over quality. These patients decide to go on dialysis despite a worse outlook relative to healthier individuals. Not all patients with increased risk factors for 3-month mortality die at 3 months. Prediction models do not accurately predict individual survival but population or cohort survival. While some patients are centered on longevity, others may base decisions on quality of life which will influence decisions regarding dialysis more than longevity. Some may have tasks to complete or relationships to mend and dialysis may afford the time to accomplish these life goals regardless of the quality of life. Individuals who value quality to a greater extent than quality ask whether they will feel better, have improved quality of life, have intolerable adverse effects on dialysis or improved uremic symptoms?

\section{Fraility}

Fraility (unintentional weight loss, decreased strength, decreased exercise intolerance, reduced gait speed and fatigue) predicts the lack of benefit to renal replacement therapy in patients over the age of 65 . Individuals with end-stage renal failure and frailty have a 2.6-fold increase in mortality and 1.4-fold risk of repeat hospitalizations in depended of age, comorbidities and disabilities [18]. Physical function, social interactions and self-care declines and falls increase further when the frail are initiated on dialysis [19-21]. Both symptom burden increases and quality of life decreases when the frail are started on dialysis. Individuals who are fail and value quality are therefore less likely to choose dialysis with this information in hand.

The development of frailty in a patient on dialysis should trigger open discussions about the goals of care, prognosis and symptom benefits or lack of symptom to ongoing dialysis [1]. Progression of frailty on dialysis suggests that dialysis is not palliative; the option of dialysis withdrawal should be discussed with patients in this situation. For those who elect not to be on dialysis, uremic symptoms can be managed with few medications [Table 1]. 
Table 1: Pharmacologic and Non-Pharmacologic Management of Uremic Symptoms.

\begin{tabular}{|c|c|}
\hline \multirow[t]{2}{*}{ Pain } & $\begin{array}{l}\text { Transdermal buprenorphine } 5 \mathrm{mcg} / \mathrm{h} \text { in opioid } \\
\text { naïve }\end{array}$ \\
\hline & Gabapentin $50-100 \mathrm{mg} / \mathrm{d}$ up to $300 \mathrm{mg} / \mathrm{d}$ \\
\hline \multirow{2}{*}{$\begin{array}{l}\text { Restless leg } \\
\text { syndrome }\end{array}$} & Gabapentin 50-100mg at night \\
\hline & Ropinirole $0.25-3 \mathrm{mg} /$ day \\
\hline \multirow{5}{*}{$\begin{array}{l}\text { Sleepdisorder/ } \\
\text { insomnia }\end{array}$} & Sleep hygiene \\
\hline & Cognitive behavior therapy \\
\hline & Melatonin 1-6mg 2 hours before sleep \\
\hline & Gabapentin $50-100 \mathrm{mg}$ at bedtime \\
\hline & Doxepin 5-10mg at bedtime \\
\hline \multirow{5}{*}{ Pruritus } & Peppermint oil emollient \\
\hline & Moisturizers \\
\hline & Gamma-linolenic acid $2.2 \%$ cream \\
\hline & Gabapentin 50-100mg/day \\
\hline & Doxepin $10 \mathrm{mg}$ at bedtime \\
\hline \multirow{3}{*}{ Nausea,vomiting } & Metoclopramide $2.5 \mathrm{mg}$ q4hour as needed \\
\hline & $\begin{array}{l}\text { Haloperidol } 0.5 \mathrm{mg} \text { q12hours increased to } 1 \mathrm{mg} \\
\text { q8h }\end{array}$ \\
\hline & Olanzapine $2.5 \mathrm{mg}$ q4- 6 hours as needed \\
\hline
\end{tabular}

\section{Conclusion}

The prognostic indicators that Thamer and colleagues used in their prognostic model are similar indicators of the fraility syndrome. Individuals who are frail prior to dialysis do not improve on dialysis and have a predictably poorer survival. Open discussions about the lack of benefits to dialysis for these individuals are important. Uremic symptoms can be managed without the need for renal replacement therapy.

\section{References}

1. Davison SN, Jassal SV. Supportive Care: Integration of PatientCentered Kidney Care to Manage Symptoms and Geriatric Syndromes. Clinical journal of the American Society of Nephrology:CJASN. 2016. doi:10.2215/CJN.01050116.

2. Bossola M, Vulpio C, Tazza L. Fatigue in chronic dialysis patients. Seminars in dialysis. 2011;24(5):550-555. DOI:10.1111/j.1525139X.2011.00956.x.

3. Bossola M, Ciciarelli C, Di Stasio E, Panocchia N, Conte GL, Rosa F, et al. Relationship between appetite and symptoms of depression and anxiety in patients on chronic hemodialysis. Journal of renal nutrition : the official journal of the Council on Renal Nutrition of the National Kidney Foundation. 2012;22(1):27-33. DOI:10.1053/j. jrn.2011.02.005.

4. Bossola M, Luciani G, Rosa F, Tazza L. Appetite and gastrointestinal symptoms in chronic hemodialysis patients. Journal of renal nutrition : the official journal of the Council on Renal Nutrition of the National Kidney Foundation. 2011;21(6):448-454. DOI:10.1053/j. jrn.2010.09.003.

5. Novak M, Winkelman JW, Unruh M. Restless Legs Syndrome in Patients With Chronic Kidney Disease. Seminars in nephrology. 2015;35(4):347-358. doi:10.1016/j.semnephrol.2015.06.006

6. Hammash MH, Lennie TA, Crawford T, Heo S, Chung ML, Biddle MJ, et al. Depressive Symptoms: Mediator of Event-Free Survival in Patients With Heart Failure. Western journal of nursing research. 2016. doi:10.1177/0193945916658883.
7. Jeon S, Redeker NS. Sleep Disturbance, Daytime Symptoms, and Functional Performance in Patients With Stable Heart Failure: A Mediation Analysis. Nursing research. 2016;65(4):259-267. doi:10.1097/NNR.0000000000000169.

8. Lum HD, Carey EP, Fairclough D, Plomondon ME, Hutt E, Rumsfeld JS, et al. Burdensome Physical and Depressive Symptoms Predict Heart Failure-Specific Health Status Over One Year. Journal of pain and symptom management. 2016;51(6):963-970. doi:10.1016/j. jpainsymman.2015.12.328.

9. Tsiligianni I, Metting E, van der Molen T, Chavannes N, Kocks J. Morning and night symptoms in primary care COPD patients: a crosssectional and longitudinal study. An UNLOCK study from the IPCRG. NPJ primary care respiratory medicine. 2016;26:16040. doi:10.1038/ npjpcrm.2016.40.

10. Duenas-Espin I, Demeyer H, Gimeno-Santos E, Polkey MI, Hopkinson NS, Rabinovich RA, et al. Depression symptoms reduce physical activity in COPD patients: a prospective multicenter study. International journal of chronic obstructive pulmonary disease. 2016;11:12871295. doi:10.2147/COPD.S101459.

11. Park SK, Larson JL. Multiple symptoms, functioning, and general health perception in people with severe COPD over time. Applied nursing research : ANR. 2016;29:76-82. doi:10.1016/j.apnr.2015.06.010.

12. Sexton DJ, Lowney AC, O’Seaghdha CM, Murphy M, O’Brien T, Casserly LF, et al. Do patient-reported measures of symptoms and health status predict mortality in hemodialysis? An assessment of POS-S Renal and EQ-5D. Hemodialysis international International Symposium on Home Hemodialysis. 2016;20(4):618-630. DOI:10.1111/hdi.12415.

13. Thamer M, Kaufman JS, Zhang Y, Zhang Q, Cotter DJ, Bang H. Predicting Early Death Among Elderly Dialysis Patients: Development and Validation of a Risk Score to Assist Shared Decision Making for Dialysis Initiation.Am J Kidney Dis. 2015 Dec;66(6):1024-32. doi: 10.1053/j. ajkd.2015.05.014. PMID: 26123861.

14.Boulos C, Salameh P, Barberger-Gateau P. Malnutrition and frailty in community dwelling older adults living in a rural setting. Clinical nutrition . 2016;35(1):138-143. doi:10.1016/j.clnu.2015.01.008.

15.Morley JE. Frailty and sarcopenia in elderly. Wiener klinische Wochenschrift. 2016

16.Pugh J, Aggett J, Goodland A, Prichard A, Thomas N, Donovan K, et al. Frailty and comorbidity are independent predictors of outcome in patients referred for pre-dialysis education. Clinical kidney journal. 2016;9(2):324-329. doi:10.1093/ckj/sfv150.

17.Musso CG, Jauregui JR, Macias Nunez JF. Frailty phenotype and chronic kidney disease: a review of the literature. International urology and nephrology. 2015;47(11):1801-1807. DOI:10.1007/s11255-0151112-z.

18. Jassal SV, Chiu E, Hladunewich M. Loss of independence in patients starting dialysis at 80 years of age or older. The New England journal of medicine. 2009;361(16):1612-1613. doi:10.1056/NEJMc0905289. Kurella Tamura M, Covinsky KE, Chertow GM, Yaffe K, Landefeld CS, McCulloch CE. Functional status of elderly adults before and after initiation of dialysis. The New England journal of medicine. 2009;361(16):1539-1547. DOI:10.1056/NEJMoa0904655.

19. Farragher J, Rajan T, Chiu E, Ulutas O, Tomlinson G, Cook WL, et al. Equivalent Fall Risk in Elderly Patients on Hemodialysis and Peritoneal Dialysis. Peritoneal dialysis international : journal of the International Society for Peritoneal Dialysis. 2016;36(1):67-70. doi:10.3747/pdi.2014.00163.

20. Vadivelu N, Hines RL. Management of chronic pain in the elderly: 
focus on transdermal buprenorphine. Clinical interventions in aging. 2008;3(3):421-430.

21. Summerfield RJ, Allen MC, Moore RA, Sear JW, McQuay HJ Buprenorphine in end stage renal failure. Anaesthesia. 1985;40(9):914.

22. Manenti L, Vaglio A, Costantino E, Danisi D, Oliva B, Pini S, et al Gabapentin in the treatment of uremic itch: an index case and a pilot evaluation. Journal of nephrology. 2005;18(1):86-91.

23. Elsaie LT, El Mohsen AM, Ibrahim IM, Mohey-Eddin MH, Elsaie ML. Effectiveness of topical peppermint oil on symptomatic treatment of chronic pruritus. Clinical, cosmetic and investigational dermatology. 2016;11(9):333-338.

24.Pour-Reza-Gholi F, Nasrollahi A, Firouzan A, Nasli Esfahani E, Farrokhi F. Low-dose doxepin for treatment of pruritus in patients on hemodialysis. Iranian journal of kidney diseases. 2007;1(1):34-37.

25. Gopaluni S, Sherif M, Ahmadouk NA. Interventions for chronic kidney disease-associated restless legs syndrome. The Cochrane database of systematic reviews. 2016;11:CD010690. 